\title{
Social Media Advertisement and its Effect in Sales Prediction - An Analysis
}

\author{
B. Subha \\ Assistant Professor, Department of Commerce \\ Kristu Jayanti College, Bangalore, Karnataka, India \\ Dttps://orcid.org/0000-0001-7200-3495
}

Manuscript ID:

MGT-2020-08023263

\section{Abstract}

Social Media Advertising plays a vital role in today's business. It helps marketers to build relationships with their customers and increase sales. Marketers are using social media to

Volume: 8 advertise their products and generate sales. Social networking sites such as YouTube, Facebook, and Instagram are essential in today's competitive business for boosting the sales of the firm. This study aims to predict the impact of social media advertising on sales of a company. The purpose

Issue: 2

Month: October

Year: 2020

P-ISSN: 2321-4643

E-ISSN: 2581-9402

Received: 10.08.2020

Accepted: 20.09.2020

Published: 01.10.2020 of this paper is to build a linear regression model that predicts sales based on money spent on YouTube advertisements. The data is analyzed using the $R$ open-source software program for statistical analysis. The $R$ is a powerful programming tool that can represent the dataset graphically concerning different parameters, and it also uses different packages available. The result of this research shows that YouTube advertising is a better predictor of company sales.

Keywords: Social Media, YouTube Advertisement, Sales, Linear Regression Model, Prediction and Advertising Budget

\section{Introduction}

In today's competitive global market, social media have become a path where marketers can spread their marketing campaigns to a broader range of customers. The tools and methods for interacting with customers have transformed significantly with the occurrence of social media; so, businesses must understand utilizing social media in a manner that is constant with their business plan (Mangold and Faulds 2009). Social media marketing helps companies to gain a competitive advantage and increase their sale.

Citation:

Subha, B. "Social Media

Advertisement and Its

Effect in Sales Prediction

- An Analysis." Shanlax

International Journal of

Management, vol. 8, no. 2, 2020, pp. 40-44.

DOI:

https://doi.org/10.34293/ management.v8i2.3263

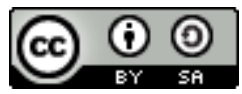

This work is licensed under a Creative Commons Attribution-ShareAlike 4.0 International License. Social media websites such as Facebook, Twitter, and YouTube have nearby to five million visitors daily, hence an essential hub for marketing. Social media has transformed the face of advertising most obviously in that it has almost eliminated the necessity for print advertising, thus providing a greener environment. There are a massive number of social media sites for advertising, but YouTube advertising is selected for this research.

\section{Review of Literature}

Supriya Verma (2016). The study is about the effect and behavior of people toward YouTube advertisements. Advertisements play a significant role in creating awareness among people about the product or service. Earlier advertisements were shown and displayed on television, radio, and newspaper, but today's digital media have replaced and conquered the old form of advertisements. In digital media, YouTube has become a common platform for advertisements. While watching YouTube, we often come across pre-roll advertisements that sometimes have an option to skip and mid-roll advertisements, which are usually between the content we are viewing on YouTube. For this research sample size is 100 . 
The questionnaire was mailed to 100 respondents (18-35 years). 56\% of respondents watch YouTube daily, and some of them use mobile to watch YouTube. 79\% of respondents come across pre-roll advertisements. According to the research, 15\% of respondents strongly agree that YouTube videos help in enhancing knowledge, and $22 \%$ agree that advertising is beneficial to consumers because it provides important information about goods and services. $64 \%$ of respondents are moderately influenced by their buying behavior. $44 \%$ said that YouTube advertisements are most influential in their buying behavior. It is recommended to advertise online as it has an impact on their buying behavior.

As Hsu and Tsou (2011) mentioned, purchasing intention is a consumers' intention to purchase products. So, it can be defined as purchasing intention is the tendency to purchase when the advertised product/service/brand is needed. Yuksel (2016), who investigated the effects of user-generated content in YouTube videos on consumers' purchase intention, found that perceived credibility, perceived usefulness, and perceived video characteristics of information in the YouTube videos positively affect purchase intention. Lai, Lai, and Chiang (2015) found that product placement and product involvement have a positive effect on purchase intention in the YouTube platform. In their study, Dehghani and Tumer (2015) determined that Facebook ads influenced the purchasing intention by affecting brand value and brand image. Dehghani et al. (2015) found that the attitude toward YouTube ads influence positively purchasing intention.

\section{Research Gap}

From the above literature review, it is recognized that many of the earlier researchers have focused on YouTube advertisement, consumer behavior, brand awareness, and purchase intention. Marketers who use YouTube Advertisement boost their revenue $49 \%$ faster than those who don't. YouTube advertisements drive sales. Moreover, other factors like the relationship between YouTube advertising budget and sales are not clearly defined in previous researches. Hence there exist a need to understand the relationship between YouTube advertising budget and sales in social media advertisement.

\section{Research Design Objective}

1. To analyze the relationship between YouTube advertising budget and sales.

2. To build a linear regression model using the training data set.

3. To make predictions of the sales of test data set using a linear regression model.

\section{Hypothesis}

Null Hypothesis: There is no statistically significant relationship between sales and the YouTube advertising budget.

Alternate Hypothesis: There is a statistically significant relationship between sales and YouTube advertising budget.

\section{Preparing the Data}

A Marketing dataset, a preloaded dataset in $\mathrm{R}$, is used for the study of this research. This marketing dataset comprises the effect of three advertising media (YouTube, Facebook, and Newspaper) on sales. The outcome variable for this research is sales, and the predictor variable is the YouTube advertising budget. The last column in the dataset denotes sales while the remaining column denotes different media advertising budgets in 1000 dollars. The dataset consists of 200 rows. Each row denotes a different advertising experiment. Once the data is loaded, a comment called head is used to look at a few samples of the data set. Similarly, to look at the end of the data set, a comment called tail is used. This is done since, in some data sets, the last few columns may comprise totals or summaries of the data, which can be unrelated. Next, the data is divided into the testing data set (30\%) and training data set (70\%) such that the training dataset will contain 145 rows, and the test dataset will have 55 rows.

Table 1 Head

\begin{tabular}{|c|c|c|c|c|}
\hline & YouTube & Facebook & Newspaper & Sales \\
\hline 1 & 276.12 & 45.36 & 83.04 & 26.52 \\
\hline 2 & 53.40 & 47.16 & 54.12 & 12.48 \\
\hline 3 & 20.64 & 55.08 & 83.16 & 11.16 \\
\hline 4 & 181.80 & 49.56 & 70.20 & 22.20 \\
\hline 5 & 216.96 & 12.96 & 70.08 & 15.48 \\
\hline 6 & 10.44 & 58.68 & 90.00 & 8.64 \\
\hline
\end{tabular}




\begin{tabular}{|c|c|c|c|c|}
\hline \multicolumn{5}{|c|}{ Table 2: Tail } \\
\hline & YouTube & Facebook & Newspaper & Sales \\
\hline 195 & 179.64 & 42.72 & 7.20 & 20.76 \\
\hline 196 & 45.84 & 4.44 & 16.56 & 9.12 \\
\hline 197 & 113.04 & 5.88 & 9.72 & 11.64 \\
\hline 198 & 212.40 & 11.16 & 7.68 & 15.36 \\
\hline 199 & 340.32 & 50.40 & 79.44 & 30.60 \\
\hline 200 & 278.52 & 10.32 & 10.44 & 16.08 \\
\hline
\end{tabular}

\section{Data Analysis and Interpretation Data Visualization}

Linear regression means a relationship between the outcome and the predictor variables are linear. The linear relationship can be simply verified by generating a scatter plot of the outcome variable (sales) vs. the predictor variable (YouTube advertising budget). The subsequent $\mathrm{R}$ code shows the relationship between the outcome variable and the predictor variable.

plot (marketing\$YouTube, marketing\$sales) abline ( model, col=2, lwd=3)

\section{Figure 1: Sales vs. YouTube Advertisement} Budget

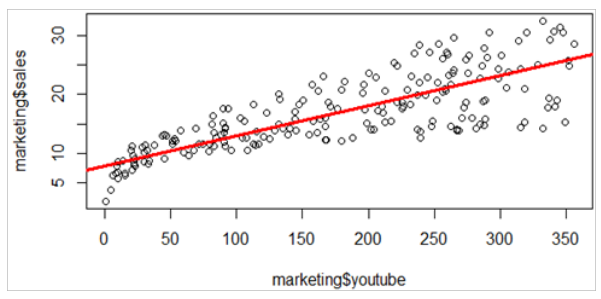

From the above graph, it is clear that there is an increasing linear relationship between the outcome variable(sales) and the predictor variable (YouTube advertising budget), which is a positive aspect. The correlation coefficient between the outcome variable and the predictor variable is calculated through the following R code.

\section{Correlation coefficient}

cor (marketing sales, marketing\$YouTube)

0.7822244

The level of association between the outcome and the predictor variables is measured by the correlation coefficient. If the correlation coefficient value is -1 , then it indicates a perfect negative relationship between the variables, and +1 indicates a perfect

positive relationship. There is a weak relationship between the two variables if the value is nearer to zero. In this research, the correlation coefficient is 0.78 , which indicates a strong positive relationship between the outcome variable and the predictor variable.

\section{Linear Regression Model}

In this paper, a simple linear model is built to predict sales units based on the advertising budget spent on YouTube. The following R code is used to find out the beta coefficients of the model.

model $<\operatorname{lm}($ sales $\sim$ YouTube, data $=$ market train $)$

\section{Coefficients}

(Intercept) YouTube

$7.821390 \quad 0.051034$

The above value indicates the beta coefficient and the intercept for the predictor variable. Hence the calculated equation is sales $=7.82+0.051 *$ YouTube. The intercept (b0) is 7.82, and the coefficient of the variable is 0.051 . Using this equation, for each new YouTube advertising budget, the number of sales units can be predicted. For a YouTube advertising budget equal zero, the expected sale is 7.82 units. For a YouTube advertising budget equal to 1000 dollars, the expected sale is $7.82+0.051 * 1000=58.8$ units.

\section{Model Summary}

Before using the model for predictions, the statistical significance of the model is assessed by exhibiting the statistical summary of the model.

Table 3: Model summary

Call:
\begin{tabular}{|l|c|c|c|c|}
\hline \multicolumn{5}{|l|}{$\operatorname{lm}($ formula $=$ sales $\sim$ YouTube, data $=$ market train $)$} \\
\hline \multicolumn{4}{|l|}{ Residuals: } \\
\hline Min & $1 \mathrm{Q}$ & Median & $3 \mathrm{Q}$ & Max \\
\hline-10.2642 & -2.1524 & -0.3782 & 2.7196 & 8.4377 \\
\hline
\end{tabular}

\begin{tabular}{|l|l|l|l|l|}
\hline \multicolumn{5}{|l|}{ Coefficients: } \\
\hline & Estimate & Std. Error & $\begin{array}{l}\mathrm{t} \\
\text { value }\end{array}$ & $\operatorname{Pr}(>|\mathrm{t}|)$ \\
\hline (Intercept) & 7.821390 & 0.644414 & 12.14 & $<2 \mathrm{e}-16^{* * *}$ \\
\hline YouTube & 0.051034 & 0.003143 & 16.24 & $<2 \mathrm{e}-16^{* * *}$ \\
\hline RSE: 3.871 on 143 degrees of freedom \\
\hline Multiple R-squared:0.8684, Adjusted R-squared:0.6459 \\
\hline F-statistic: 263.7 on 1 and 143 DF, p-value: $<2.2 \mathrm{e}-16$ \\
\hline
\end{tabular}




\section{Interpretation}

The $\mathrm{p}$-value of t-static can be used to determine whether the null hypothesis can be rejected or not. The higher the t-statistic and the lower the p-value, the more significant is the predictor. In this research, both the p-values for the intercept and the predictor variable are highly significant. Hence the predictor variable YouTube advertisement is significantly related to the outcome variable sales. Hence the null hypothesis is rejected. It is normal to measure the goodness -of- fit of the linear regression model, once the null hypothesis is rejected. The quality of linear regression fit is typically measured using two related measures, the residual standard error (RSE) and the R-squared statistic.

In this research for the training dataset, residual standard error is 3.87 , meaning that the observed sales value deviates from the true regression line by approximately 3.87 units on average. In this research, the mean value of sales of the training dataset is 16.83 , and so the percentage error is $3.87 / 16.83=22 \%$, which is a low residual error. Thus, lower the RSE, the model fits best with the data. The value of $\mathrm{R}$ square in this research is 0.8684 . The value of $\mathrm{R}$-square usually ranges from 0 to 1 . The model with a high $\mathrm{R}$ square will be better. The linear regression model of this research is having good accuracy since the $\mathrm{R}$ square value is high.

\section{Sales Prediction}

The performance of the regression model is evaluated by making predictions with test data. new data $<$ - data. frame $($ YouTube $=\mathrm{c}(0,1000))$ predict (model, new data)

12

\section{$7.82139 \quad 58.85568$}

The result shows a surge of 58 units in sales for the YouTube advertising budget equal to 1000 dollars. The accuracy of the model is tested by Root mean squared error and R-square values. The model is better with lower RMSE and higher R-square values.

RMSE (res, market_test\$sales)

4.069838

R2 (res, market test\$sales)

0.8495986 mean (market_test\$sales)

16.65818

The computed R-square value for the test dataset is 0.84 . The above $\mathrm{R}$-square value indicates the predicted outcome value by the model is highly correlated with the observed outcome value in the test datasets. The calculated Root mean square value for the test dataset is 4.06 . The error rate for the test dataset is $24 \%(4.06 /$ mean $)$, which is low. Hence the model accuracy is good.

\section{Findings}

1. The relationship between YouTube advertising budget and sales is linear and additive.

2. There is a strong relationship between the outcome variable and the predictor variable.

3. There is a statistically significant relationship between the YouTube advertising budget and sales.

4. The linear regression model built in this research fits very well with the data.

5. According to the prediction of the linear regression model for the YouTube advertising budget of 1000 dollars, an increase of 58 units of sales is expected.

\section{Conclusion}

YouTube advertising has realized unbelievable growth in the last decade and is the main marketing channel for many marketers. YouTube advertisement helps to build brand awareness, increase market share, and drive sales. Marketers have conventionally turned to YouTube for branding. Later they have invested time to understand the impact of YouTube advertisements on sales. From this study, it is clear that there is a significant relationship between YouTube advertising budget and sales. This research concludes YouTube advertising is a better predictor of company sales.

\section{References}

Abdullah, Mohammad. "The Impact of Social Media on Sales." Entrepreneur, 2017.

"Advertising - A Linear Regression." 2017, https://rstudio-pubs-static.s3.amazonaws. com/308616_a98a1796a30a4883814d8367f0 0d1992.html 
Amit. "Linear Regression Adverstising Data." RPubs, https://rpubs.com/datascientiest/249959.

Bevans, Rebecca. “A step-by-step Guide to Linear Regression in R.” Scribbr, 2020.

Dehghani, Milad, and Mustafa Tumer. "A Research on the Effectiveness of Facebook Advertising on Enhancing Purchase Intention of Consumers." Computers in Human Behavior, vol. 49, 2015, pp. 597-600.

"FAQ: What is Social Advertising \& How Does It Impact My Sales?" LYFE Marketing, 2019.

Gonzalo, Frederic. "The Impact of Social Media in Ad Spending [Infographic].” Frederic Gonzalo's Blog, 2018.

"How Does Social Media Marketing Increase Sales?" Marketing Source, 2019.

Hsu, Hsuan Yu., and Hung-Tai Tsou. "Understanding Customer Experiences in Online Blog Environments." International Journal of Information Management, vol. 31, no. 6, 2011, pp. 510-523.

Jenkins, Lisa D. "YouTube Marketing: The Ultimate YouTube for Business Guide." Social Media Examiner, 2017.

Karaman, Barış. "Predicting Sales." Towards Data Science, 2019.

Lai, Ying-Fang, et al. "Exploring the Effects of Online Video Advertising Message Display, Product Placement, and Product Involvement on Advertising Effectiveness." International Journal of Economies and Statistics, vol. 3, 2015, pp.117-127.

Lewis, Michael. "How to Use Social Media Marketing Strategy to Increase Sales.” Money Crashers.

"Linear Regression." UC Business Analytics $R$ Programming Guide, https://uc-r.github.io/ linear_regression.
"Linear Regression Essentials in R." STHDA, 2018. Mangold, Glynn W., and David J. Faulds. "Social Media: The New Hybrid Element of the Promotion Mix." Business Horizons, vol. 52, no. 4, 2009, pp. 357-365.

Nanji, Ayaz. "How Social Media Advertising Affects Sales." Marketing Profs, 2014.

Prabhakaran, Selva. "Linear Regression." $r$-statistics.co.

Sidhu, Rishi. "Linear Regression in R - Example in Code." Medium, 2019.

"Simple Linear-Regression using R." GeeksforGeeks, 2018.

"Simple Linear Regression in R." Kaggle, https:// www.kaggle.com/amitdhakre13/simplelinear-regression-in-r

"Simple Linear Regression in R." STHDA, 2018.

"Social Media Marketing for Businesses." WordStream, https://www.wordstream.com/ social-media-marketing.

"Understanding how YouTube ads can impact Offline Sales: Sales Correlation Case Studies." https://www.thinkwithgoogle.com/ intl/en-154/marketing-collections/youtube/ youtube-ad-impact.

Verghese, Sonali. "Predicting the Impact of Social Media Advertising on Sales with Linear Regression." Towards Data Science, 2020.

Verma, Supriya. "Study on the Effect and Behaviour of People toward YouTube Advertisements." International Journal of Management and Economics Invention, vol. 2, no. 2, 2016, pp. 541-546.

Yuksel, Hale Fulya. "Factors Affecting Purchase Intention in YouTube videos." The Journal of Knowledge Economy \& Knowledge Management, vol.11, no. 2, 2016, pp. 33-47.

\section{Authour Details}

Dr. B. Subha, Assistant Professor, Department of Commerce, Kristu Jayanti College, Bangalore, Karnataka, India, Email ID: subhaashok3@gmail.com 